\title{
Nodular Graphite Formation in Pore-containing White Cast Iron Sintered by means of Direct Electric Resistance Heating*
}

\author{
By Kenzo Hanawa**, Zenshiro Hara*** \\ and Kiyoaki Akechi***
}

\begin{abstract}
Using an electric resistance sintering aparatus, $2-5 \% \mathrm{C}$ cast iron powder compacts containing flake graphite were heated very rapidly to melt the central part of the compacts. During rapid cooling, the pores were frozen in a white cast iron matrix. The pore-containing white cast irons were annealed at 873-1223 $\mathrm{K}$ for $1.8 \mathrm{ks}$ under dry hydrogen flow, and then cooled in air or in a furnace. Nodular graphite $5 \sim 10 \mu \mathrm{m}$ in diameter was distributed depending on the distribution of pores which existed before annealing. However, in the pore-free specimens remelted at $1723 \mathrm{~K}$ for $0.6 \mathrm{ks}$, no nodular graphite was formed. The crystal structure of the nodular graphite was polycrystalline, with the c-axis of all crystallites oriented in a radial direction, similar to that of conventional nodular graphite crystallized in a melt. These results indicate that the nodular graphite can be formed by annealing of the pore-containing white cast iron made from any kinds of cast iron powder irrespective of carbon centents. This is because carbon atoms undissolved in austenite are decomposed from cementite and precipitate as graphite on the surface of pores and then fill them up during annealing.
\end{abstract}

(Received December 15, 1980)

\section{Introduction}

Utilization of pulverized cast iron machining swarf for powder metallurgy appears to open new prospects because not only this process is useful for resource censervation ${ }^{(1)}$ but also $\mathrm{P} / \mathrm{M}$ products made from this powder show excellent mechanical properties owing to graphite nodularization $^{(2)}$.

In previous work $^{(3)(4)}$ the authors have investigated graphite nodularization in $\mathrm{P} / \mathrm{M}$ products, with the following results:

(1) Graphite nodules (5 10 $\mu \mathrm{m}$ in diameter) are obtained by long time sintering or powder forging of cast iron powders and also of $\mathrm{Fe}-$ Si-C mixed powders containing about $1 \% \mathrm{C}$.

(2) The graphite nodules are formed because carbon atoms which are dissolved in austenite during sintering supersaturate during cooling and precipitate as graphite into spheroidal pores in $\mathrm{P} / \mathrm{M}$ products.

* This paper was originally published in Japanese in J. Japan Inst. Metals, 45 (1981), 438.

** Graduate School, University of Tokyo, Roppongi, Minato-ku, Tokyo 106, Japan.

*** Institute of Industrial Science, University of Tokyo, 7-22-1 Roppongi, Minato-ku, Tokyo 106, Japan.
(3) In the case of powders containing carbon in excess of $2 \%$, nodular graphite cannot be obtained because carbon atoms which are rejected from austenite during cooling precipitate onto irregular-shaped graphite which is undissolved in austenite during sintering.

The previous results suggest that morphologies of defects in a matrix such as pores and graphite undissolved in austenite determine morphologies of graphite in $\mathrm{P} / \mathrm{M}$ products. Consequently, it is expected that microstructures with graphite nodules will be also obtained even from cast iron powder containing more than $2 \% \mathrm{C}$, provided that irregular-shaped graphite which remains undissolved in austenite at a solid-phase sintering temperature is removed leaving spheroidal pores in specimens.

Thus we can consider that the following process provide microstructures consisting of graphite nodules. The cast iron powder compacts are heated above the liquidus to dissolve all the graphite into the liquid phase. The melt is cooled at a rate sufficient to solidify as white cast iron in which carbon atoms in excess of the solubility in austenite exist as the metastable phase of cementite. At the same time gas bubbles are frozen which are generated during rapid melting of the powder compacts. The 
white cast irons containing pores are subsequently annealed between the eutetoid and eutectic temperatures so that the excess carbon atoms will be decomposed from the metastable phase of cementite and precipitate into pores as the stable phase of graphite.

In order to accomplish the process, an electric resistance sintering apparatus was used which can heat and cool powder compacts very rapidly. This paper describes the results that microstructures with nodular graphite are achieved through the process.

\section{Experimental Procedure}

Cast iron powder pulverized from a gray cast iron machining swarf is used. During pulverizing, free graphite was separated from a matrix and removed by a cyclone machine which decreased carbon content down to $2 \%$. The chemical composition and particle size distribution are shown in Tables 1 and 2, respectively. As shown in Photo. 1, graphite exists as coarse flakes and also in fine arrangement in the cast iron powder.

3,4 and $5 \% \mathrm{C}$ cast iron powders are prepared by mixing graphite powder with the $2 \% \mathrm{C}$ cast iron powder in a ball-mill.

An electric resistance sintering (ERS) apparatus is used to melt and solidify the powder compacts to obtain a pore-containing white cast iron specimen. ERS is one of the $\mathrm{P} / \mathrm{M}$

Table 1 Chemical composition of cast iron powder.

\begin{tabular}{ccccc}
\hline \hline $\mathrm{C}$ & $\mathrm{Si}$ & $\mathrm{Mn}$ & $\mathrm{P}$ & $\mathrm{S}$ \\
\hline 2.00 & 2.68 & 0.50 & 0.08 & 0.07 \\
\hline \hline
\end{tabular}

Table 2 Particle-size distribution of cast iron powder.

\begin{tabular}{ccc}
\hline \hline & Mesh & mass \% \\
\hline & +32 & 0.05 \\
-32 & +45 & 0.15 \\
-45 & +65 & 4.05 \\
-65 & +100 & 26.4 \\
-100 & +150 & 22.9 \\
-150 & +200 & 24.8 \\
-200 & +250 & 9.35 \\
-250 & +325 & 6.90 \\
-325 & & 5.40 \\
\hline \hline
\end{tabular}

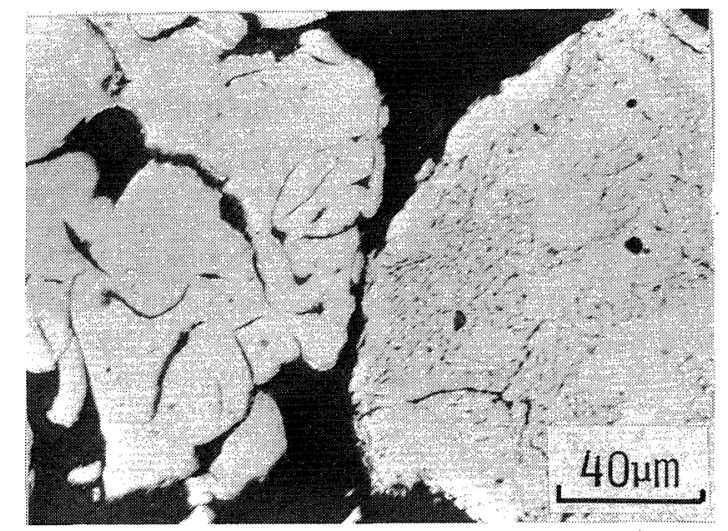

Photo. 1 Graphite morphologies in cast iron powder.

techniques which uses juole heat evolved by a direct electric current passing through pressed powder ${ }^{(5)}$. Using the method a powder compact can be heated and cooled very rapidly. We can roughly know the heating and cooling rate by direct measurements of surface temperatures during ERS of iron powder. It revealed that only about $1 \mathrm{~s}$ electric current flow heats the compacts up to $1500-1700 \mathrm{~K}$ and after the current is cut off, specimens are cooled to 400 $500 \mathrm{~K}$ within $2-3 \mathrm{~s}^{(6)}$. Therefore, by controlling input power we can readily produce liquid phase in a sintered product.

Figure 1 shows a schematic diagram of the sintering tool of the ERS apparatus. Inner sides of metal dies are insulated with plasma-sprayed alumina coating. The powder charged into a

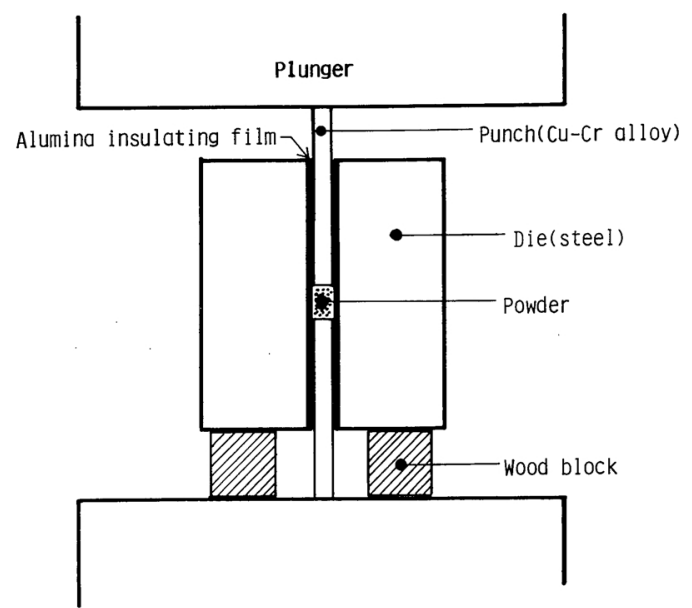

Fig. 1 Schematic diagram of the sintering tool of ERS apparatus. 
die-cavity is pressed using $\mathrm{Cu}-\mathrm{Cr}$ alloy punches and at the same time heated by a direct electric current. Because it was to melt the central part of specimens in our experiments, the ERS conditions were set as shown in Table 3 which generate more input power than usual. Furthermore, in order to avoid the spill-out of a melt from the dies and to keep the bubbles formed during melting, a stopper was set which controls the down-stroke of the upper punch.

The specimens $(4 \mathrm{~mm} \times 7 \mathrm{~mm} \times 50 \mathrm{~mm})$ made by ERS apparatus were annealed under dry hydrogen flow at various temperatures in the range from 873 to $1323 \mathrm{~K}$ for $1.8 \mathrm{ks}$, and then cooled in air $\dagger$ or in a furnace. Cooling rate at around $773-1283 \mathrm{~K}$ were approximately 3 or $0.1 \mathrm{~K} / \mathrm{s}$ respectively.

Microstructures were observed by optical
Table 3 Electric resistance sintering conditions.

\begin{tabular}{ll}
\hline \hline $\begin{array}{l}\text { Electric-resistance-sintering } \\
\text { apparatus }\end{array}$ & $45 \mathrm{~kW}, 3 \times 10^{4} \mathrm{~N}$ \\
\hline Insulating film & $\begin{array}{c}\text { Alumina coating of } \\
\text { plasma spray }\end{array}$ \\
Set-in current efficiency & $80 \%$ \\
Non-load voltage & $6.9 \mathrm{~V}$ \\
Mass of powder & $12 \mathrm{~g}$ \\
Pressure & $150 \mathrm{MPa}$ \\
Area of pressure and current & $4 \times 50 \mathrm{~mm}^{2}$ \\
$\quad$ application & $1.5 \mathrm{~s}$ \\
Current-flow time & $56 \mathrm{~kJ}$ \\
Input power &
\end{tabular}

microscopy and scanning electron microscopy (SEM). The three-dimensional aspects of graphite nodules were also observed using SEM after etching away the metallic matrix in hydro-chloric acid.

\section{Experimental Results}

Photograph 2 presents various observatoins
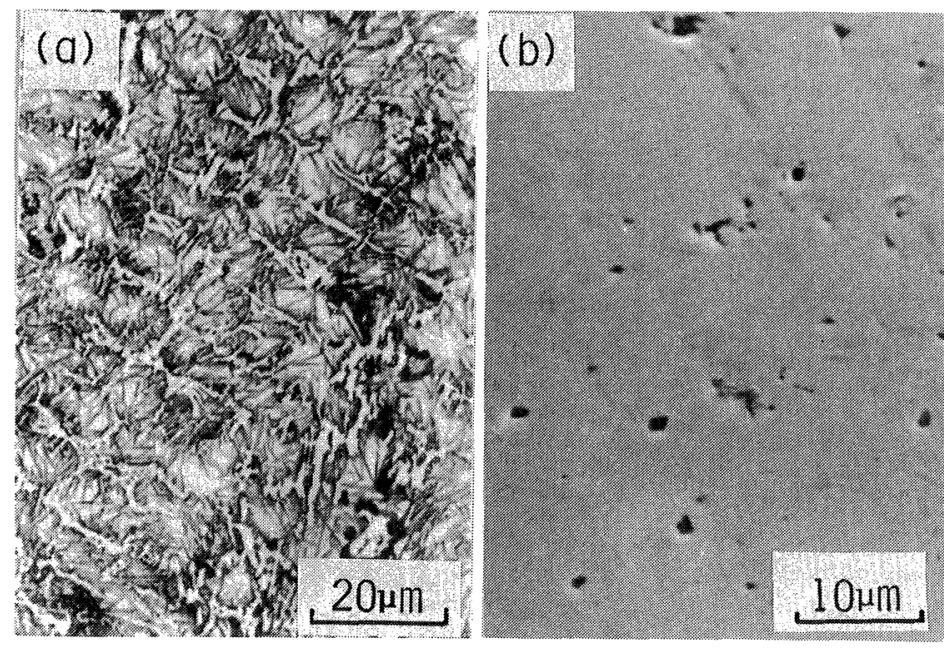

Photo. 2 Various observations on $2 \% \mathrm{C}$ specimen as solidified by ERS apparatus (a) Microstructure (etched in nital), (b) Reflected electron image (aspolished), (c) $\mathrm{C} \mathrm{K}_{\alpha}$ image (as-polished) showing nonprecence of any kinds of graphite, (d) Highly magnified secondary electron image (as-polished) showing empty hollow of frozen pores.
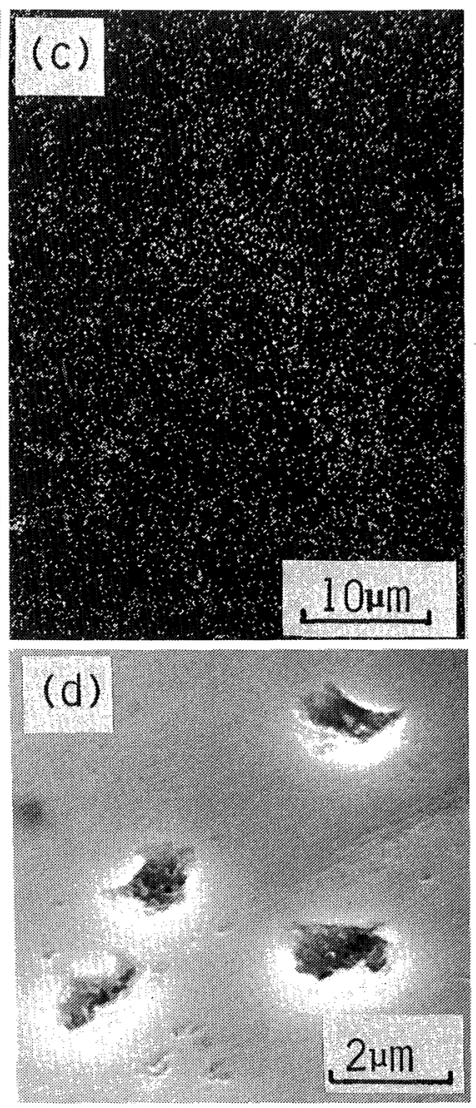
(a)
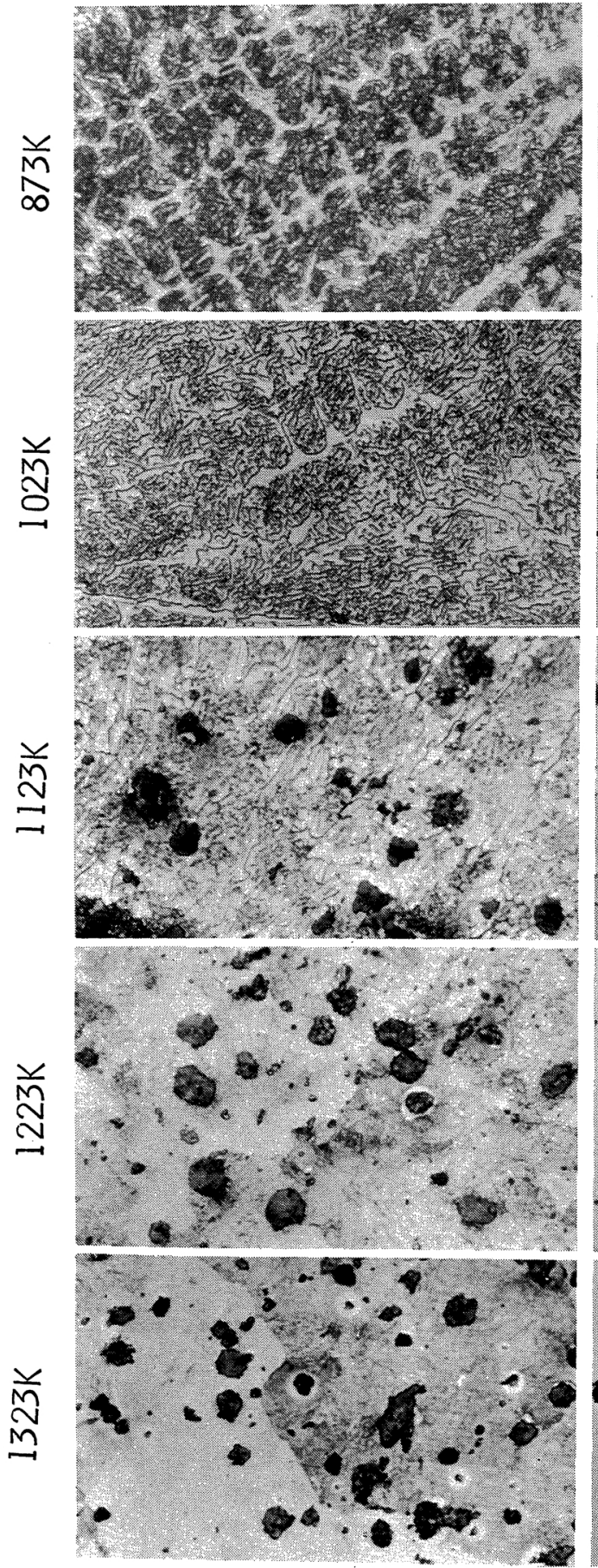

(b)
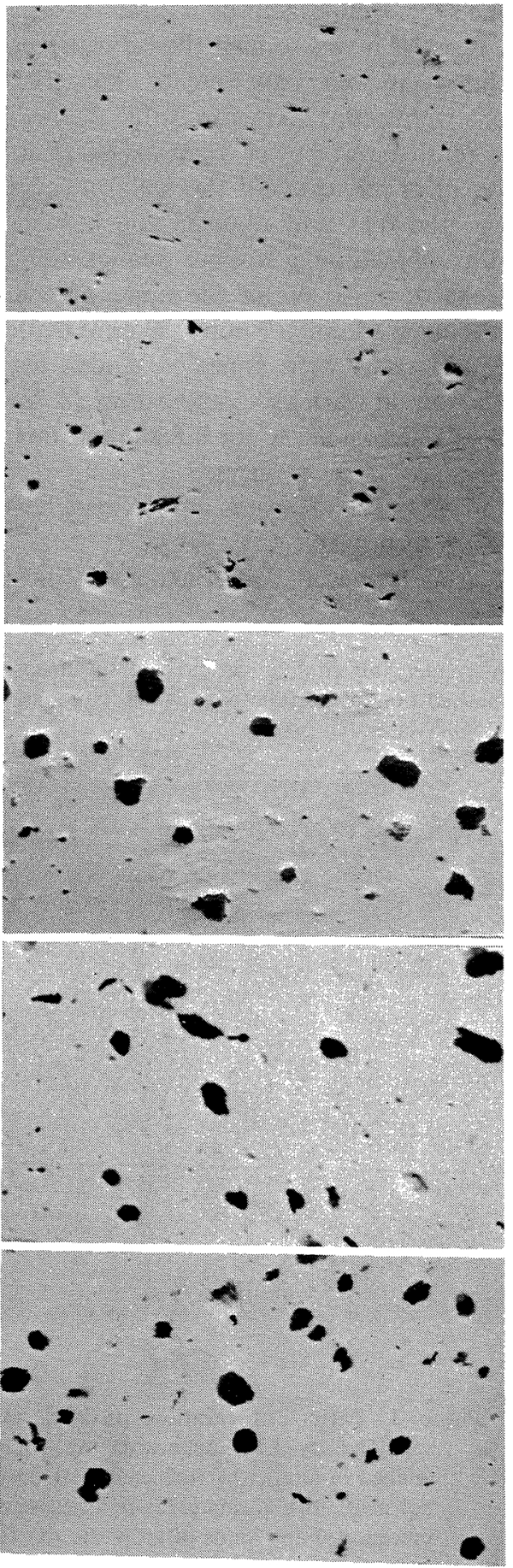

$20 \mu \mathrm{m}$

Photo. 3 (a) Microstructures (etched in nital) and (b) reflected electron images (as-polished) of $2 \% \mathrm{C}$ specimens solidified by ERS apparatus annealed at various temp. for $1.8 \mathrm{ks}$, and air cooled. 
on a specimen from the $2 \% \mathrm{C}$ cast iron powder compact melted and soldified very rapidly using ERS apparatus: (a) microstructure (etched in nital), (b) reflected electron image (as-polished), (c) $\mathrm{C} \mathrm{K}_{\alpha}$ image (as-polished), and (d) highly magnified secondry electron image (aspolished). The microstructure (a) is a hypoeutectic white cast iron structure showing dendrites of primary austenite which has changed to martensite, and ledebulite in the interdendritic regions. The microstructure clarifies that the cast iron powder was melted and subsequently the melt which dissolved all graphite was solidified so rapidly that carbon atoms in excess of the solubility in austenite appear as cementite. The reflected electron image (b) reveals that pores are distributed which look like black spots and were distinguished as pores by (c) and (d); $\mathrm{C} \mathrm{K}_{\alpha}$ image (c) indicates a homogeneous carbon atom distribution showing the absence of undissolved graphite, and the highly magnified secondary electron image (d) points out black spots are empty hollow. This indicates that rapid cooling just after melting caused pores to be frozen before escaping from a melt.

Thus we confirm that we can make porecontaining white cast iron from the cast iron powder using ERS apparatus.

Photograph 3 presents (a) optical micrographs (etched in nital) and (b) reflected electron images (as-polished) of pore-containing white cast irons from the $2 \% \mathrm{C}$ powder, annealed at $873,1023,1123,1223$, and $1323 \mathrm{~K}$ for $1.8 \mathrm{ks}$, and subsequently air cooled. As the temperature is increased, white cast iron structures decompose into structures consisting of graphite nodules and pearlite.

In the specimens annealed at $873 \mathrm{~K}$, below the eutectoid temperature, eutectic cementite in ledeburite remains unchanged, although dendritic martensite has transformed to peartite. In the specimens annealed at $1023 \mathrm{~K}$, around the eutectoid temperature, the distribution of eutectic cementite has varied. Nevertheless, graphite does not appear. In the specimens annealed at 1123,1223 , and $1323 \mathrm{~K}$, above the eutectoid temperature, eutectic cementite has decomposed and graphite nodules

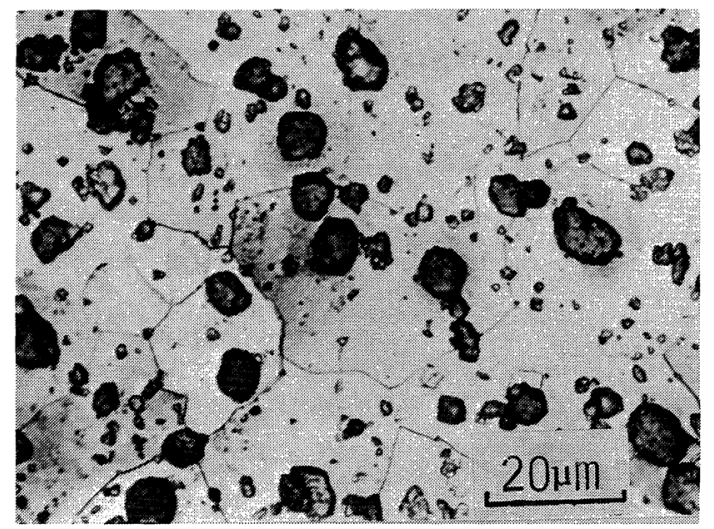

Photo. 4 Microstructure (etched in nital) of $2 \% \mathrm{C}$ specimen solidified by ERS apparatus, annealed at $1323 \mathrm{~K}$ for $1.8 \mathrm{ks}$, and furnace cooled.

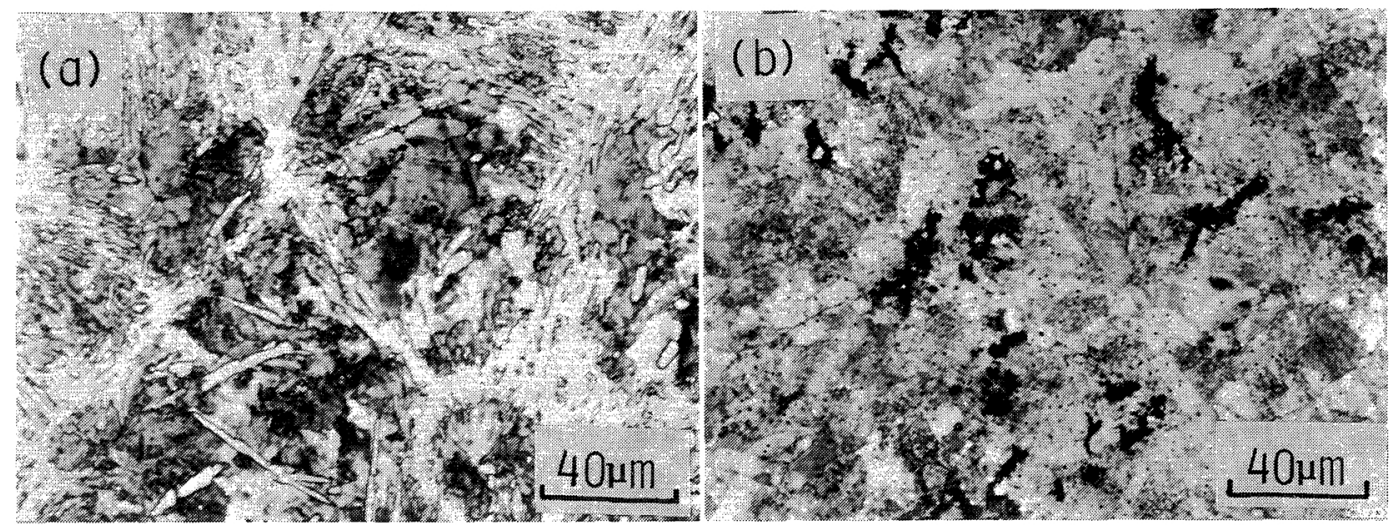

Photo. 5 (a) Microstructure (etched in nital) of $2 \% \mathrm{C}$ specimen solidified by ERS apparatus, melted again at $1723 \mathrm{~K}$ for $0.6 \mathrm{ks}$, and air cooled (b) microstructure (etched in nital) of $2 \% \mathrm{C}$ specimen solidified by ERS apparatus, melted at $1723 \mathrm{~K}$ for $0.6 \mathrm{ks}$, air cooled, subsequently annealed at $1323 \mathrm{~K}$ for $1.8 \mathrm{ks}$, and finally air cooled. 
(a)
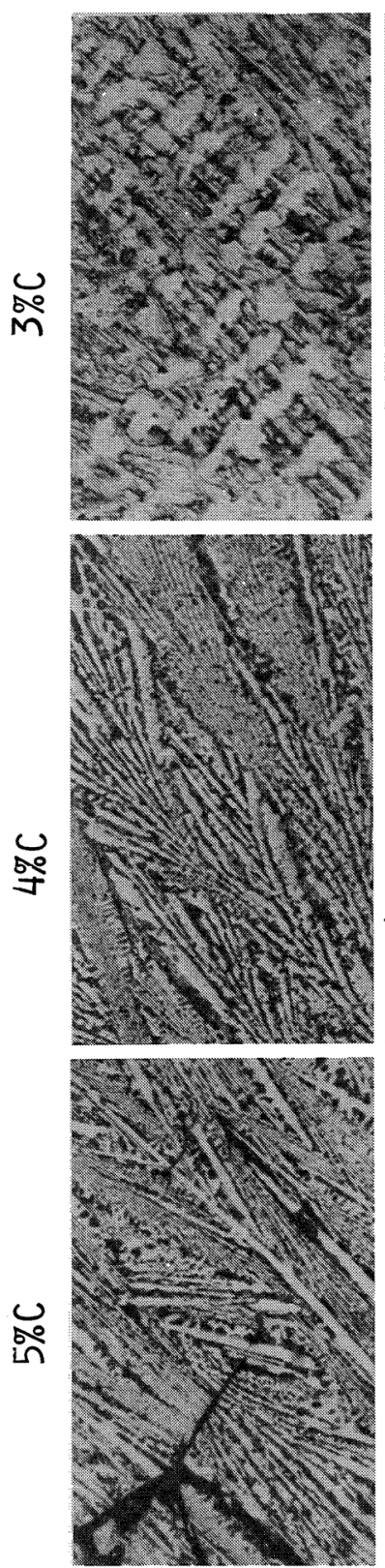

(b)
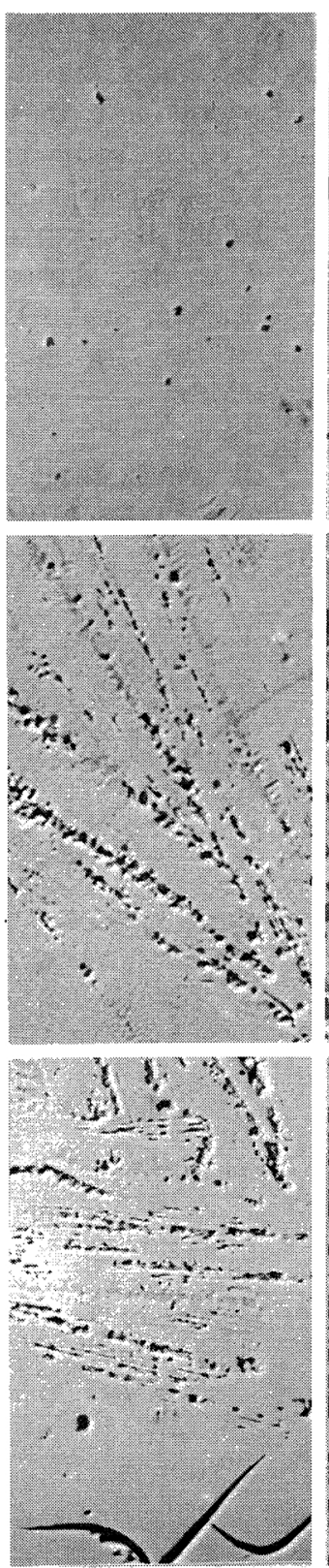

(c)

(d)
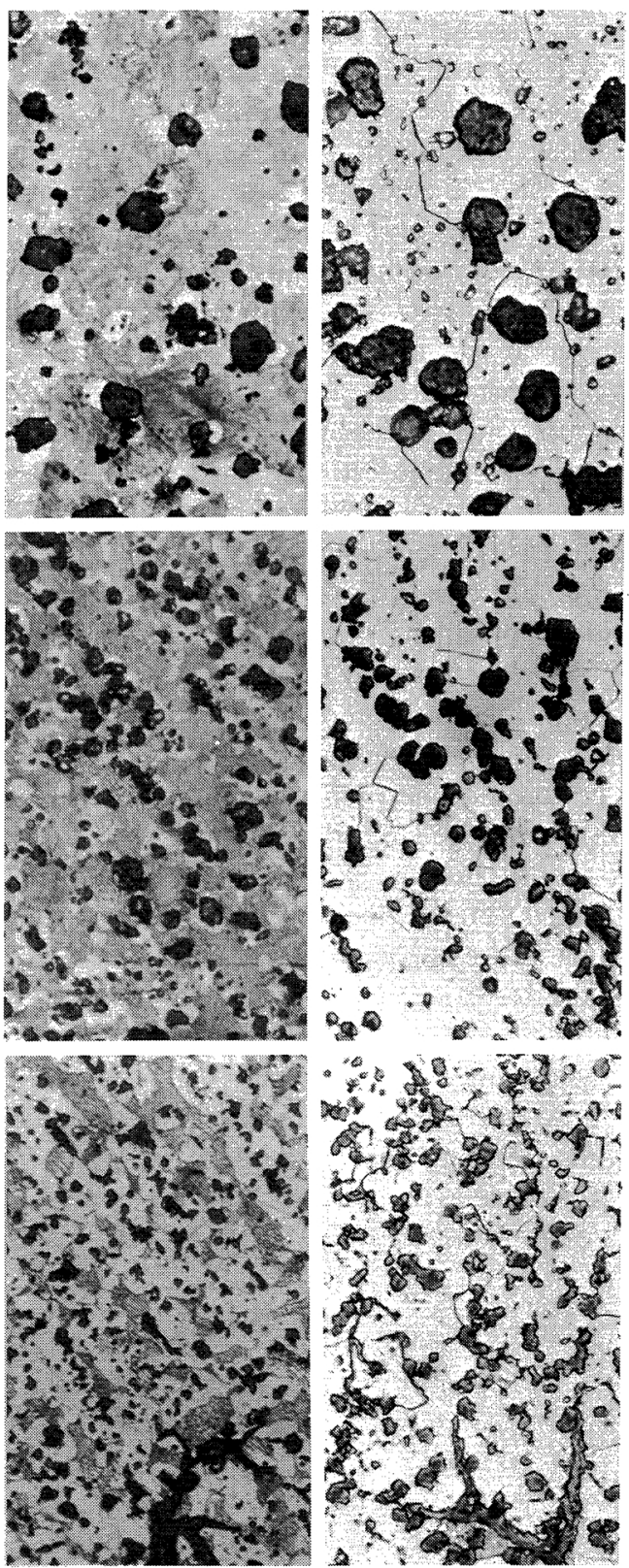

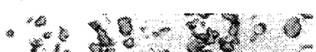

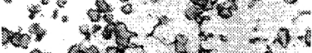

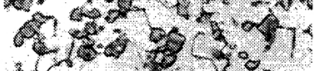

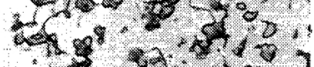

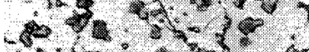
$280-3,5$

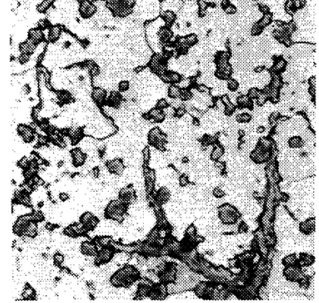
$20 \mu \mathrm{m}$

Photo. 6 (a) Microstructures of specimens as solidified by ERS apparatus (3\%C-etched in alkaline sodium picrate, $4 \%, 5 \% \mathrm{C}$-etched in nital) (b) reflected electron images (aspolished) of specimens as solidified by ERS apparatus (c) microstructures (etched in nital) of specimens solidified by ERS apparatus, annealed at $1323 \mathrm{~K}$ for $1.8 \mathrm{ks}$, and air cooled (d) microstructures (etched in nital) of specimens solidified by ERS apparatus, annealed at $1323 \mathrm{~K}$ for $1.8 \mathrm{ks}$, and furnace cooled. 
are detected; although the white cast iron structure still remains after annealing at $1123 \mathrm{~K}$ for $1.8 \mathrm{ks}$, eutectic cementite has completely decomposed resulting in structures consisting of graphite nodules and a pearlite matrix after annealing at $1223,1323 \mathrm{~K}$ for $1.8 \mathrm{ks}$.

In addition, Photo. 4 shows an optical micrograph of a furnace cooled, not air cooled, specimen subjected to $1323 \mathrm{~K}-1.8 \mathrm{ks}$ annealing. Graphite nodules are distributed in a ferritic matrix. This microstructure is the same as that of conventional nodular graphite cast iron ${ }^{(7)}$ produced by casting and annealing.

To investigate the role of pores, pores were taken away from the white cast iron. Photograph 5 presents optical micrographs of a specimen (a), melted and solidified very rapidly using ERS apparatus, held at $1723 \mathrm{~K}$ for 0.6 $\mathrm{ks}$, and then air cooled; of the specimen (b) subsequently annealed at $1323 \mathrm{~K}$ for $1.8 \mathrm{ks}$, and finally air cooled. Photograph 5(a) indicates that the melt free from pores, as a result of holding at $1723 \mathrm{~K}$ which is well above the liquidus, solidifies as white cast iron under air cooling. Although the annealing of this pore-free white cast iron provides a microstructure consisting of graphite and pearlite, only irregular-shaped graphite, not nodular graphite, appears as shown in Photo. 5(b).

Photograph 6 presents (a) optical micrographs and (b) reflected electron images (aspolished) of pore-containing white cast irons from 3, 4, and $5 \% \mathrm{C}$ powder. Microstructures (a) shows typical white cast iron structures which vary with carbon contents; $3 \% \mathrm{C}$ specimen consists of austenite dendrite and ledeburite; $4 \% \mathrm{C}$ specimen completely forms ledebutite; $5 \% \mathrm{C}$ specimen develop needlelike primary cementite and patches of flake graphite set in a background of ledeburite. Reflected electron images (b) reveal pore distributions in the specimens as identified by Photo. 2. These suggest that pore distributions depend on modes of solidification.

These specimens were annealed at $1323 \mathrm{~K}$ for $1.8 \mathrm{ks}$ and then cooled in air or in a furnace. Optical micrographs of these specimens are presented in Photo. 6(c) and (d). These indicate that the 3,4 , and $5 \% \mathrm{C}$ powders as well as the $2 \% \mathrm{C}$ powder provide the microstructures in which graphite nodules are distributed; patches of flake graphite are found, however, in the specimens from $5 \% \mathrm{C}$ powder owing to the difficulty in stabilising the massive cementite; during annealing carbon atoms derived from decomposing cementite partly precipitate onto the flake graphite, but the remainder precipitate into nearest pores forming graphite nodules. The results from 3, 4, and $5 \% \mathrm{C}$ powders show that the pore distributions determine the graphite nodule distributions.

Finally, to examine the crystal structure of graphite nodules, the cross-section (a) and appearance (b) of graphite nodule are shown in Photo. 7. Because the polycrystalline structure with $c$-axis of all crystallites pointing in a radial direction is observed, it can be concluded that the crystal structure is the same as that of conventional nodular graphite ${ }^{(7)}$; although the nodule diameter $(5-10 \mu \mathrm{m})$ is from one-fifth
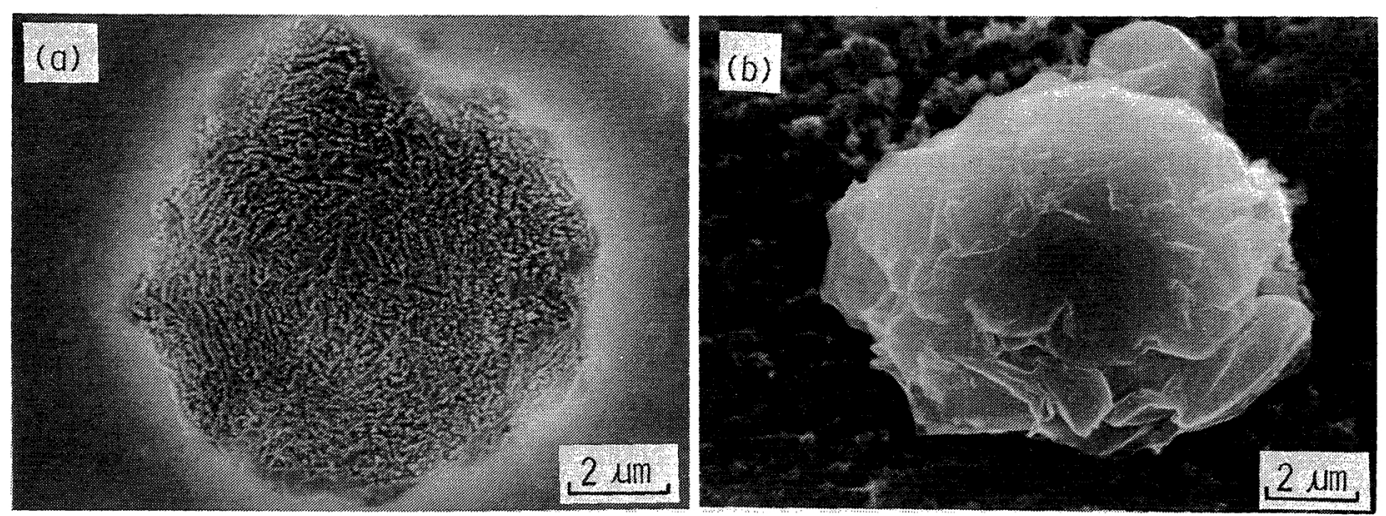

Photo. 7 SEM photographs of section (a) and morphology (b) of nodular graphite. 
to one-tenth of the usual diameter of nodular graphite.

\section{Discussion}

The results are summarized as follows:

(1) Graphite nodules are formed irrespective of carbon contents during graphitizing treatment in pore-containing white cast irons. On the contrary, in the pore-free white cast iron, precipitated graphite does not nodularize even if it is graphitized in the same way.

(2) Graphite nodule distributions depend on pore distributions.

(3) The crystal structure of graphite nodules obtained in our experiments is the same as that of conventional nodular graphite which is polycrystalline with the $c$-axis of all crystallites pointing in the radial direction. The above results are discussed as below.

The previous papers ${ }^{(3)(4)}$ describe that carbon contents of cast iron powder must be less than the maximum solubility in austenite to obtain nodular graphite by solid-phase sintering. The result of (1), however, indicates that even from cast iron powder containing more than $2 \% \mathrm{C}$, nodular graphite can be obtained when the graphite insoluble in austenite is changed to cementite, at the same time pores are induced in the metastable dual phase of $\gamma+\mathrm{Fe}_{3} \mathrm{C}$ associated with $\mathrm{Si}$, a strong graphitizing element. This is because cementite decomposes and the excess carbon atoms which cannot be dissolved in austenite precipitate into pores as the stable form of graphite.

In addition, if there are some other sites than pores where carbon atoms tend to precipitate as graphite (for example, undissolved graphite between powder particle boundaries reported in the previous papers ${ }^{(3)(4)}$, and patches of flake graphite in white cast iron from the $5 \% \mathrm{C}$ powder in this paper), growing graphite takes various forms determined by the morphologies of the sites.

The result of (2) further demonstrates the fact that graphite nodules are formed because carbon atoms precipitate into spheroidal pores. Note that in 2 and $3 \% \mathrm{C}$ specimens pores are distributed more homogeneously than in 4 and $5 \% \mathrm{C}$ specimens, because dendrites of austenite catch pores between them; this is apparent in Photo. 8.

We can conclude from the result of (3) that the same mechanism must be applied to the formation of the two kinds of nodular graphite; one is obtained in our experiments and the other is nodular graphite found in conventional castings. This is explained as follows.

Yamamoto, Chang, Kawano et al. has investigated systematically the mechanism of nodular graphite formation and reported the conclusion $^{(8) \sim(13)}$ : graphite morphologies are determined by the morphologies of defects which govern the growing direction of the graphite; it follows that the spherical shape of

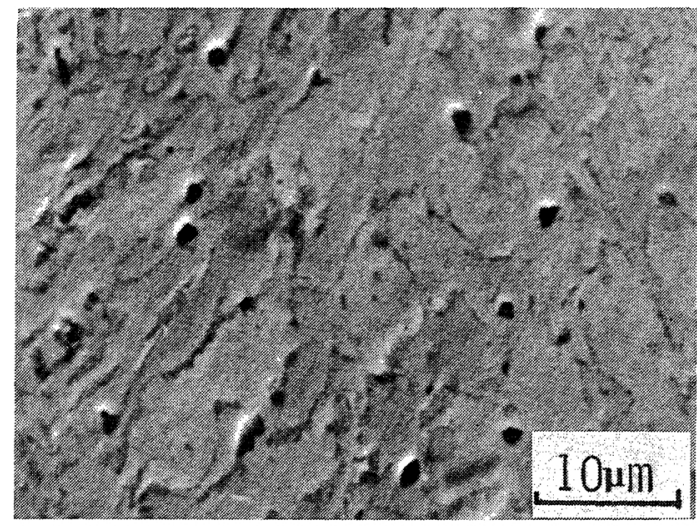

Photo. 8 Reflected electron image (etched in alkaline sodiun picrate) of $3 \% \mathrm{C}$ specimen as solidified by ERS apparatus.

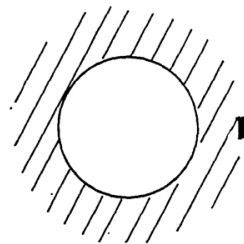

(a)

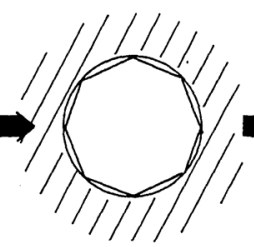

(b)

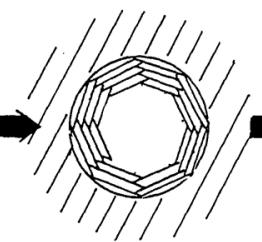

(c)

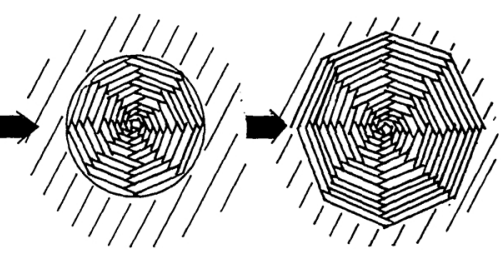

(d)

(e)

Fig. 2 Process of nodular graphite formation. 
gas-bubbles in a melt or of cavities in a solid accounts for the spherical morphology of graphite nodules. Thus, the formation of nodular graphite which is precipitated from a solid as well as crystallized from a melt are schematically represented in Fig. 2. (a) Because pore/liquid or pore/solid interfaces act as the most preferential sites for carbon atoms to crystallize or precipitate as graphite, graphite nucleates at random on the pore surface. (b) These graphite nuclei will grow along the interface as plates parallel to the (0001) basal plane because the crystal structure ${ }^{\dagger}$ have a strong tendency to preferential growth along the (0001) basal plane owing to the remarkable anisotropy of chemical bonding and structure. (c) After covering the surface of the pore with thin plates of graphite, next plates nucleate and also grow along the (0001) basal plane, consequently thickening takes place inward. (d) As the result of piling up of graphite flakes in a pore which plays the role of a spherical framework, graphite nodules reveal the polycrystalline structure with the $c$-axis of all crystallites pointing in a radial direction. (e) After the filling of pores graphite nodules will grow outward, if carbon atoms further precipitate onto the graphite nodules.

During the outward growth after filling the pores, the spheroidal morphology of the graphite remains unchanged, unless there are preferential directions for carbon atoms to precipitate; for example, grain boundaries crossing the pores. Under the conditions, however, such as too many carbon atoms exist for the size of pores, and growth rate is too slow, the chances increases that graphite nodules touch grain boundaries, phase boundaries of $\gamma+\mathrm{Fe}_{3} \mathrm{C}$, or non-metallic inclusions during growth. If they touch the defects, centrifugal growth will be disturbed because carbon atoms tend to precipitate along these directions.

Eventually, it is concluded that morphologies and distributions of graphite formed during

$\dagger$ The carbon atoms are arranged in a hexagonal array in layers whose distance $\left(3.35 \times 10^{-10} \mathrm{~m}\right)$ is by far greater than that between closest neighbors in a layer $\left(1.42 \times 10^{-10} \mathrm{~m}\right)$. annealing are determined firstly by morphologies and distributions of pores in the white cast iron; secondly by various defects which move and alter during annealing.

\section{Conclusions}

By use of the electric resistance sintering apparatus, pore-containing white cast irons are produced from $2-5 \% \mathrm{C}$ cast iron powder. Annealing of the pore-containing white cast irons resulted in microstructures consisting of graphite nodules. It is clarified according to the gas bubble theory that these graphite nodules are formed because carbon atoms which cannot be dissolved in austenite are decomposed from cementite and then precipitate into pores as graphite.

As already pointed out, carbon contents of cast iron powder must be less than the maximum solubility in austenite (for example, $1.5 \%$ $\mathrm{C}$ in the presence of $2.5 \% \mathrm{Si})^{(14)}$ so that nodular graphite is formed by solid-phase sintering. The results of the present work, however, indicate that nodular graphite can be formed from any kinds of cast iron powder irrespective of carbon contents if graphite undissolved in austenite are changed to cementite and at the same time pores are introduced.

\section{REFERENCES}

(1) T. Nakagawa and C. S. Sharma: Modern Development of Powder Met. Vol. 9, Metal Powder Industries Federation, American Powder Metallurgy Inst., Princeton, New Jersey, (1977), p. 347.

(2) T. Nakagawa and F. S. Dai: Seisan Kenkyu, 32 (1980), No. 3, 129 (in Japanese).

(3) K. Hanawa, K. Akechi and Z. Hara: Trans. Japan Inst. Metals, 21 (1980), 765.

(4) K. Hanawa, K. Akechi and Z. Hara: J. Japan Inst. Metals, 44 (1980), 943 (in Japanese).

(5) K. Akechi and Z. Hara: J. Japan Inst. Metals, 43 (1979), 1031 (in Japanese).

(6) T. Sakai and Z. Hara: Seisan Kenkyu, 23 (1971), 248 (in Japanese).

(7) A. R. Bailey and L. E. Samnels: Foundry Metallography, Metallurgical Services Laboratories Limited, Betchworth, Surrey, England, (1971), p. 166, p. 137.

(8) S. Yamamoto, B. Chang, Y. Kawano, R. Ozaki and Y. Murakami: Metal Sci., 9 (1975), 360.

(9) B. Chang, S. Yamamoto, Y. Kawano and R. Ozaki: J. Japan Inst. Metals, 41 (1977), 464, 471, 479, 564, 571, 1019, 1025 (in Japanese). 
(10) B. Chang, S. Yamamoto, Y. Kawano and R. Ozaki: J. Japan Foundrymen's Society, 49 (1977), 269 (in Japanese).

(11) S. Yamamoto, T. Yasuda and Y. Murakami: J. Japan Inst. Metals, 41 (1977), 1194 (in Japanese).
(12) S. Yamamoto, B. Chang, Y. Kawano, R. Ozaki and Y. Murakami: Metal Sci., 11 (1978), 239.

(13) Y. H. Lee and Y. Kawano: J. Japan Inst. Metals, 44 (1980), 339 (in Japanese).

(14) J. E. Hilliard and W. S. Owen: J. Iron Steel Inst., 172 (1952), Nov., 268. 